\title{
Sodium, potassium and water metabolism in myxoedema
}

\author{
IVOR SURVEYOR* \\ M.D., M.R.C.P.
}

\author{
Registrar, Department of Nuclear Medicine, Leeds General Infirmary
}

\begin{abstract}
Summary
In a combined radioactive isotope study, $\mathrm{Na}_{e}, \mathrm{~K}_{e}$, bromine space and total body water were measured in a group of fourteen hypothyroid subjects. These were compared with a 'control' group.

Total body water and $\mathrm{Na}_{e}$ were found to be increased in the hypothyroid subjects.

In seven subjects, the measurements were repeated after treatment with thyroid hormone. Most of the subjects lost weight and showed a decrease in total body water, but changes in $\mathrm{Na}_{e}, \mathrm{~K}_{e}$ and bromine space were variable.

The cause and nature of the fluid and electrolyte retention in myxoedema are discussed and reasons are advanced for the apparent inconsistencies in the results obtained in this and other studies.
\end{abstract}

\section{Introduction}

Hypothyroidism is associated with increased body weight and fluid retention. Pitting oedema and serous effusions have been reported in some cases (Kocen \& Atkinson, 1963). Various studies have been made of electrolyte metabolism in myxoedema, especially with balance techniques and radioactive isotope dilution methods. Increased total exchangeable sodium $\left(\mathrm{Na}_{e}\right)$ before treatment has been reported by Aikawa (1956) and whereas some authors have described no consistent change after treatment (Arons, Vanderlinde \& Nusimwich, 1956), others have observed a decrease in $\mathrm{Na}_{e}$ after administration of thyroid hormone (Aikawa, 1956; Munro, Renschler \& Wilson, 1958a). Reduced total exchangeable potassium $\left(\mathrm{K}_{e}\right)$ in myxoedema and also a variable reduction after treatment have been reported (Aikawa, 1956; Arons et al., 1956; Munro et al., 1958a). Similarly, balance studies (Soffer et al., 1954; Cohen, 1963) and single injections of thyroid hormone have yielded inconsistent results of both sodium and potassium balance (Byrom, 1933; Asper, Selenkow \& Plamondon, 1953; Rawson et al., 1953).

In order to further investigate the nature of the salt and water abnormality in myxoedema, body composition was studied with radioactive isotope

\footnotetext{
* Present address: Senior Medical Registrar, Llandough Hospital, Penarth, Glam.
}

tracers and the measurements were repeated after replacement therapy in some subjects.

\section{Materials and methods}

A total of sixteen myxoedematous subjects were studied. The isotope dilution studies were first carried out on a group of fourteen hypothyroid females with a mean age of 54 years (range 29-76 years), none of whom was in heart failure or had serous effusions. These were compared with a 'control' group of twenty-three females, with a mean age of 53 years (range 29-78 years), who were all hospital convalescent in-patients. Although the age distribution was similar in both groups, it was found that the 'control' group were leaner than average. Their mean weight was $89 \%$ (range 59-129) of average weight, as predicted from the Society of Actuaries (1959) tables of body build. The isotope measurements were repeated on five of these hypothyroid females and two other hypothyroid males (Cases 5 and 6), after treatment of their myxoedema. All were clinically euthyroid at the time of the second measurement. This was performed in a mean time of 7.4 weeks (range 3-14 weeks) after treatment was commenced. The diagnosis of myxoedema was confirmed by radioactive tracer studies and the Achilles jerk times (Miles \& Surveyor, 1965).

A combined isotopes study using ${ }^{24} \mathrm{Na},{ }^{42} \mathrm{~K},{ }^{82} \mathrm{Br}$ and tritium oxide was carried out. This method has been described in detail elsewhere (Surveyor, 1967; Surveyor \& Hughes, 1968). Briefly, it consisted of the oral administration of approximately $40 \mu \mathrm{Ci}$ of ${ }^{24} \mathrm{Na}, 120 \mu \mathrm{Ci}$ of ${ }^{42} \mathrm{~K}, 20 \mu \mathrm{Ci}$ of ${ }^{82} \mathrm{Br}$ and $300-500$ $\mu \mathrm{Ci}$ of tritium oxide. Urine and plasma samples were obtained at 6 and $24 \mathrm{hr}$ and all other urine passed during the 24-hr equilibration period was collected to allow for radioactivity excreted. The conventional 24-hr equilibration period was used for ${ }^{24} \mathrm{Na},{ }^{42} \mathrm{~K}$ and ${ }^{82} \mathrm{Br}$. A 6-hr period was considered sufficient for tritium oxide (Pinson \& Langham, 1957). ${ }^{82} \mathrm{Br}$ was separated from ${ }^{24} \mathrm{Na}$ and ${ }^{42} \mathrm{~K}$ by passing the urine and plasma samples through ion exchange resin columns of IRA 400 and Zeo Carb 225. ${ }^{24} \mathrm{Na}$ and ${ }^{42} \mathrm{~K}$ were separated from each other 
TABLE 1. Total body water, total exchangeable sodium, total exchangeable potassium and bromine space in 'control' and hypothyroid females

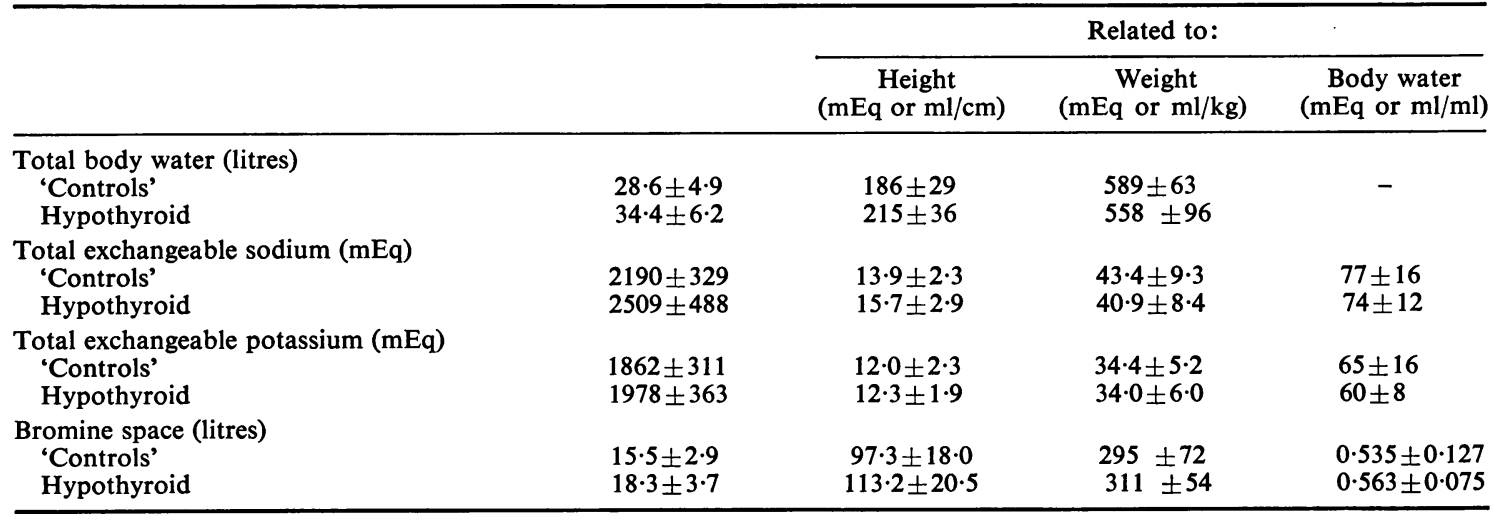

Table shows mean \pm 1 SD for all measurements.

by discriminating between the different radiations emitted by the two isotopes (Munro, Renschler \& Wilson, 1958b; Veall \& Vetter, 1958). The samples for tritium oxide were counted in an automatic liquid scintillator spectrophotometer, after a vacuum distillation process. Urine specific activity was used in the calculation of $\mathrm{K}_{e}$ and plasma samples were used in the estimation of $\mathrm{Na}_{e}$ and total body water (Surveyor \& Hughes, 1968).

The theoretical errors in counting, pipetting and flame photometry were calculated for each measurement. These were: $\mathrm{Na}_{e} \pm 3 \%, \mathrm{~K}_{e} \pm 5 \%$, bromine space $\pm 2 \%$ and total body water $\pm 3 \%$. In addition, there may be biological variations in the distribution of the indicators throughout the body compartments. The errors involved in combined radioactive isotope dilution measurements have been studied in detail by Platts et al. (1965).

\section{Results}

The hypothyroid group with a mean height of $159 \cdot 7 \pm 6 \cdot 2 \mathrm{~cm}$ were significantly taller than the 'control' group, whose mean height was $154 \cdot 5 \pm 7 \cdot 5$ $\mathrm{cm}(t=2 \cdot 1, P<0.025)$. They were also significantly heavier $(t=2.6, P<0.01)$ than the 'controls', with mean weights of $62.6 \pm 13.8$ and $52.1 \pm 10.1 \mathrm{~kg}$, respectively. Table 1 shows the mean $\mathrm{Na}_{e}, \mathrm{~K}_{e}$, bromine space and total body water estimation in the hypothyroid and 'control' groups and their relationship to height, weight and total body water. Total body water and $\mathrm{Na}_{e}$ were measured in all twenty-three 'controls' and fourteen hypothyroid subjects. $\mathrm{K}_{e}$ was measured in sixteen of the 'controls' and twelve hypothyroid subjects and bromine space was measured in fourteen 'controls' and ten hypothyroid patients.

The mean total body water in the hypothyroid group was significantly greater than in the 'control' group $(t=3 \cdot 1, \quad P<0.0025)$. This difference was maintained when related to height $(t=2 \cdot 6, P<0.01)$, but when related to body weight, the difference was not significant.

The bromine space in the hypothyroid group was significantly greater $(t=2.01, P<0.05)$. However, when expressed in relation to height, weight or total body water, there was no difference between the two groups. The mean $\mathrm{Na}_{e}$ in the myxoedematous subjects was also significantly greater than in the 'controls' $(t=2.29, P<0.025)$. This difference was still evident when $\mathrm{Na}_{e}$ was related to height $(t=2 \cdot 02$, $P<0.05)$. There was no significant difference in relation to weight or total body water. The $\mathrm{K}_{e}$ in the hypothyroid group did not differ significantly from the 'control' group. Neither were there any differences when $\mathrm{K}_{e}$ was related to height, weight or total body water.

Fig. 1 shows the measurements before and after treatment in seven hypothyroid subjects. Six lost weight. The mean loss was $2.0 \mathrm{~kg}(t=3.02, P<$ 0.0125 ). Five of the subjects who lost weight also showed a decrease in total body water, the mean loss over the six being 3.7 litres $(t=2.2, P<0.05)$. The total body water of Case 6 was not included in the mean, since the large decrease was not matched by any change in weight. The $\mathrm{Na}_{e}$ was repeated in all seven subjects and showed an increase in two, no change in one and a decrease in the other four. The greatest loss was $770 \mathrm{mEq}$ in Case 5. The mean loss was $234 \mathrm{mEq}(t=1 \cdot 47$, which is not significant). The bromine space was repeated in five subjects. There was a small mean loss of 0.6 litres but two cases showed a gain. $\mathrm{K}_{e}$ was repeated in six of the subjects. Two showed a slight increase and the remainder lost potassium. The mean loss was $125 \mathrm{mEq}(t=1 \cdot 12$, which is not significant). In two subjects plasma sodium increased by 6 and $8 \mathrm{mEq} / 1$. The mean in- 


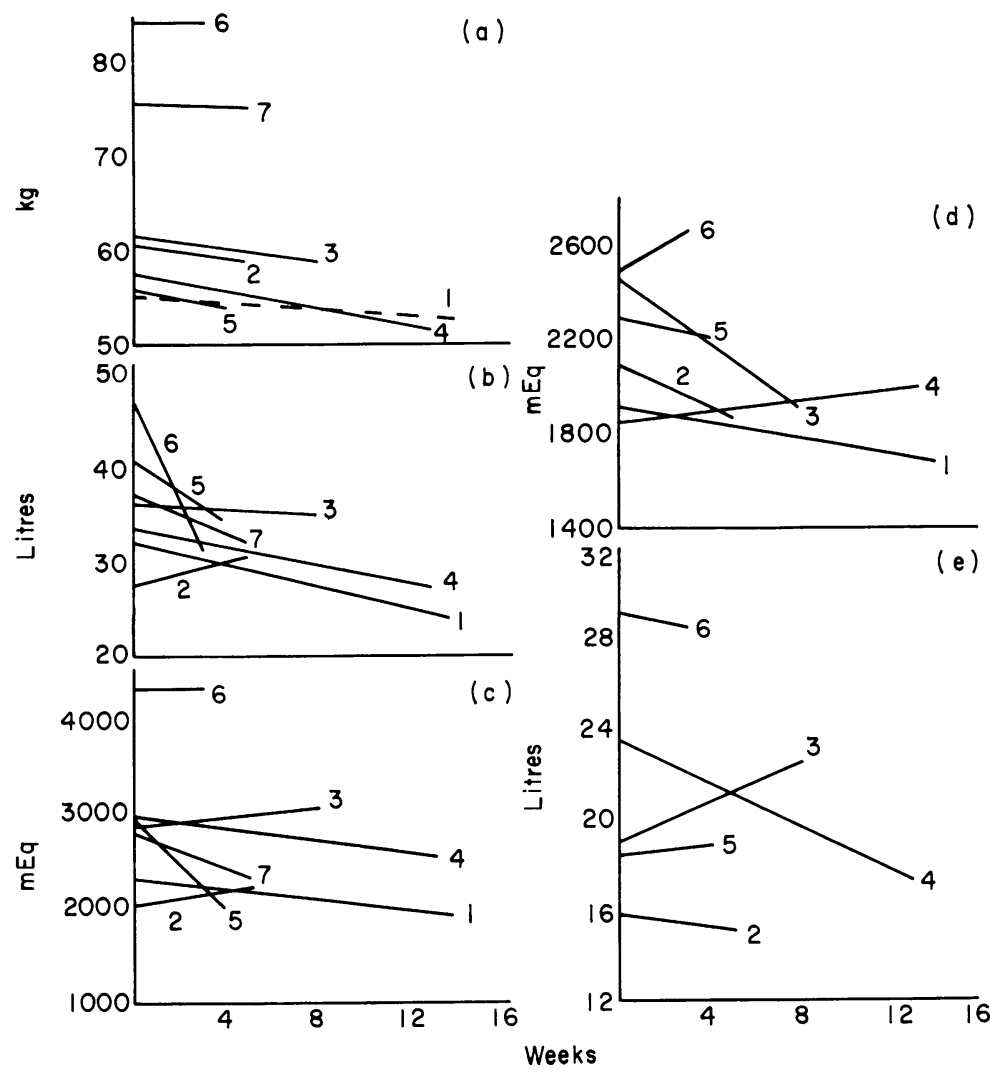

FIG. 1. Myxoedema before and after treatment-changes in body spaces and weight. (a) Body weight, (b) total body water, (c) total exchangeable sodium, (d) total exchangeable potassium, and (e) broniine space. Case numbers shown at end of lines.

crease was $2 \mathrm{mEq} / 1$. The small mean increase in plasma potassium was not significant.

\section{Discussion \\ Total body water}

The present study confirms the presence of fluid retention in myxoedema. There was a significant increase in total body water in the hypothyroid group of females, compared with the 'control' group. The hypothyroid group were taller, but the total body water was increased in this group in relation to height, suggesting that the extra lean body mass of the taller subjects did not account for all the increased total body water. The greater weight of the hypothyroid group was due to increased body water and not to additional adipose tissue, since this would have caused a 'dilution effect' in the total body water to weight ratio. After treatment, there was a significant loss of both weight and total body water. The consistency of the weight and fluid loss is shown by the fact that six of the seven subjects lost weight and five of these six lost body water.
The cause of the fluid retention in myxoedema has been the subject of various theories. It has been suggested that there is increased capillary permeability (Lange, 1944). Baker \& Hamilton (1957) demonstrated thickened capillaries with periodic acid-Schiff stains in necropsy material. They thought that this provided a basis for increased capillary permeability. But it would seem unlikely that increased permeability alone could account for the water and salt retention.

The ability to excrete a water load is impaired in some hypothyroid subjects (Crispell, Parsons \& Sprinkle, 1954; Hubble, 1955; Vogt, 1960). However, this is an intermittent finding, which was reported in two out of five subjects in one study (Surveyor, 1967). An abnormally low glomerular filtration rate and reduced renal blood flow have been recorded (Corcoran \& Page, 1947; Ford et al., 1961). It is also known that myxoedema affects the cardiovascular system (Zondek, 1944). In a study of twenty cases of myxoedema, McBrien \& Hindle (1963) found sixteen with enlarged heart shadows, 
seven of whom had raised venous pressure and oedema. But on the basis of the circulatory response to the Valsalva manoeuvre (Sharpey-Schafer, 1955), only one of these subjects was in cardiac failure. Goldberg \& Reivich (1962) and Pettinger, Talner \& Ferris (1965) have suggested that there may be inappropriate secretion of antidiuretic hormone. Thus the low plasma sodium recorded in myxoedema (Aikawa, 1956) has been explained on a dilution basis. Rawson et al. (1953) found a rise in plasma sodium after single injections of thyroid hormone and Munro et al. (1958a) and Cohen (1963) reported a rise in those subjects whose plasma sodium was low before treatment. In the subjects of Munro et al. (1958a), the plasma sodium rose, in spite of a decrease in $\mathrm{Na}_{e}$. In Case 2 of the present series, the rise in plasma sodium from 133 to $139 \mathrm{mEq} / \mathrm{l}$ cannot be accounted for by excretion of excess water, since the total body water increased by 3.7 litres and the $\mathrm{Na}_{e}$ increased by $265 \mathrm{mEq}$.

\section{Exchangeable sodium}

Aikawa (1956) found an increased $\mathrm{Na}_{e}$ in four out of six hypothyroid subjects and in this present study, the $\mathrm{Na}_{e}$ was significantly increased in the hypothyroid group. The $\mathrm{Na}_{e}$ in relation to height was also greater, but in relation to weight or total body water there was no significant difference. Although there was a mean loss of $\mathrm{Na}_{e}$ after treatment, individual results varied, as other authors have found (Arons et al., 1956; Aikawa, 1956). This variable response to treatment has also been found in balance studies (Soffer et al., 1954; Cohen, 1963), as well as after single injections of thyroid hormone (Rawson et al., 1953; Asper et al., 1953). Soffer et al. (1954) found a transient increase in extracellular space (thiosulphate space) in two subjects after treatment. In this study, changes in bromine space were not constant. The bromine space was larger !n the hypothyroid group, but unlike total body water and $\mathrm{Na}_{e}$, was not increased in relation to height. Thus it seems that the excess water in myxoedema may be present in a form not penetrable by ${ }^{82} \mathrm{Br}$. Both $\mathrm{Na}_{e}$ and bromine space increased in Case 3, but in Case 5 a fall in $\mathrm{Na}_{e}$ accompanied a rise in bromine space, and in Case $2, \mathrm{Na}_{e}$ increased while the bromine space decreased.

\section{Exchangeable potassium}

In agreement with the findings of Aikawa (1956) and Munro et al. (1958a), there was no difference in $\mathrm{K}_{e}$ between the two groups. Arons et al. (1956) found a low $\mathrm{K}_{e}$ in half their subjects and a reduced $\mathrm{Na}_{e} / \mathrm{K}_{e}$ ratio in all their nine subjects. The decrease in $\mathrm{K}_{e}$ after treatment in this study was not significant, although again, individual results varied. Munro et al. (1958a) reported a decrease in five out of six subjects and Aikawa (1956) and Arons et al. (1956) also found a decrease in some subjects. Cohen (1963) found five out of his six patients to be in potassium balance at the end of the period of observation. Single injections of thyroid hormone have not been found to cause any constant effect on potassium excretion (Rawson et al., 1953; Asper et al., 1953). No constant changes in plasma potassium have been demonstrated either before or after treatment.

The nature of the fluid and sodium retention in myxoedema

Ord (1878) found excess mucin in the skin, kidneys, heart and liver of his first case. Brewer (1951) examined a man who died after a 10-year history of myxoedema. He found the tongue infiltrated with a mixture of mucoproteins containing hyaluronic acid and chondroitin sulphuric acid. Infiltrations in the pericardium consisted of a histochemically distinct mucoprotein. These abnormal proteins would be of too large a molecular weight to exert osmotic attraction. But as a hydrophilic gel, they would be able to attract salt and water. Dogs made hypothyroid with ${ }^{131}$ I, showed a high concentration of mucopolysaccharide complexes in the skin (Goldberg \& Chaikoff, 1952). The skin of myxoedematous subjects has been shown by Mancini, Garberi $\&$ de la Balze (1952) to contain these substances, which decrease after treatment with thyroid hormone (Gabrilove, Ludwig \& Soffer, 1952). Byrom (1933) and Wiener et al. (1955) thought that break-up of these mucopolysaccharide complexes was responsible for the increase in sodium and water excretion after treatment. The findings of the present study are compatible with the suggestion that the excess water and sodium in myxoedema is bound in these mucopolysaccharide complexes. If these mucopolysaccharides have differing chemical compositions, as suggested by Brewer (1951), then different rates of breakdown after treatment can be expected. This would account for the variability between subjects in the rate of decrease of total body water and sodium after treatment. It is possible that the changes are fluctuant and that serial measurements would reveal expansions and contractions of the body spaces, until the euthyroid state is attained. Thus the varying duration of therapy before repeating the measurements may also account for some lack of consistency in the results. As Soffer et al. (1954) have pointed out, there must also be a balance between the mobilization of water and electrolytes and renal ability to excrete the excess load.

\section{Acknowledgments}

I should like to express my thanks to Dr C. J. Hayter, physician in charge of the Department of Nuclear Medicine 
at Leeds General Infirmary, for allowing me to study patients under his care and for his help and advice throughout the studies. I also thank the staffs of the Departments of Nuclear Medicine and Chemical Pathology at Leeds General Infirmary for their help; Dr A. H. Smith for his help with the radioactive isotope measurements; and the Department of Medical Photography at Llandough Hospital, Cardiff, for preparing Fig. 1.

This work was incorporated in an M.D. thesis for the University of Bristol.

\section{References}

AIKAWA, J.K. (1956) The nature of myxoedema-alterations in serum electrolyte concentrations and radiosodium space and in exchangeable sodium and potassium content. Ann. intern. Med. 44, 30.

Arons, W.L., Vanderlinde, R.J. \& Nusimwich, B. (1956) Exchangeable body sodium and potassium measurement in hyper and hypothyroidism. J. clin. Endocr. 16, 974 (Abstract).

Asper, S.P., Selenkow, H.A. \& Plamondon, C.H. (1953) A comparison of the metabolic activities of 3.5.3.L-triiodothyronine and L-thyroxine. Bull. Johns Hopk. Hosp. 93, 164.

BAKER, S.M. \& Hamilton, J.D. (1957) Capillary changes in myxoedema. J. lab. Invest. 6, 218.

BREWER, D.B. (1951) Myxoedema-autopsy report with histochemical observations on nature of mucoid infiltrations. J. Path. Bact. 63, 503.

Byrom, F.B. (1933) Nature of myxoedema. Clin. Sci. 1, 273.

COHEN, R.D. (1963) Water and electrolyte metabolism during the treatment of myxoedema. Clin. Sci. 25, 293.

Corcoran, A.C. \& PAGE, I.H. (1947) Specific renal functions in hyperthyroidism and myxoedema. J. clin. Endocr. 7, 801.

Crispell, H.K., Parson, W. \& Sprinkle, P. (1954) Cortisone resistant abnormality in diuretic response to ingested water in primary myxoedema. J. clin. Endocr. 14, 640.

Ford, R.V., OWen, J.C., CuRd, G.W., MaYer, J.H. \& SPURR, C.L. (1961) Kidney function in various thyroid states. J. clin. Endocr. 21, 548.

Gabrilove, J.L., Ludwig, A.W. \& Soffer, L.J. (1952) Effect of thyroid hormone and thyrotropin on the ground substance and connective tissue. J. clin. Endocr. 12, 966 (Abstract).

Goldberg, M. \& Reivich, M. (1962) Studies on the mechanism of hyponatraemia and impaired water excretion in myxoedema. Ann. intern. Med. 56, 120.

GoldBeRG, R.C. \& CHAIKofF, I.L. (1952) Myxoedema in radiothyroidectomised dog. Endocrinology, 50, 115.

Hubble, D. (1955) Endocrine relations. Lancet, i, 1.

Kocen, R.S. \& AtKinson, M. (1963) Ascites in hypothyroidism. Lancet, i, 527.

LANGE, K. (1944) Capillary permeability in myxoedema. Amer. J. med. Sci. 208, 5 .

McBrien, D.J. \& Hindle, W. (1963) Myxoedema and heart failure. Lancet, i, 1066.
Mancini, R.E., Garberi, J.C. \& De la Balze, F.A. (1952) Mucoproteins of the connective tissue of the skin in generalized myxoedema. J. nat. Cancer Inst. 13, 247.

Miles, D.W. \& SuRVeYor, I. (1965) Role of the ankle jerk in the diagnosis and management of thyroid disease. Brit. med. J. $1,158$.

MunRo, D.S., Renschler, H. \& Wilson, G.M. (1958a) Exchangeable potassium and sodium in hyperthyroidism and hypothyroidism. Metabolism, 7, 124.

Munro, D.S., Renschler, H. \& Wilson, G.M. (1958b) The assay of mixtures of sodium-24 and potassium-42 in clinical tracer studies, with particular reference to the measurement of T.E.S. and T.E.K. Phys. in Med. Biol. 2, 239.

ORD, W. (1878) Clinical lecture on myxoedema. Brit. med. J. 1,671 .

Pettinger, W.A., Talner, L. \& Ferris, T.F. (1965) Inappropriate secretion of antidiuretic hormone due to myxoedema. New Engl. J. Med. 272, 362.

Pinson, E.A. \& Langham, W.H. (1957) Physiology and toxicology of tritium in man. J. appl. Physiol. 10, 108.

Platts, M.M., Cox, J.R., Horn, M.E. \& Miller, H. (1965) Limitations and accuracy of simultaneous measurement of total exchangeable sodium, potassium and bromine space in man. Brit. J. Radiol. 38, 558 (Abstract).

Rawson, R.W., Rall, J.E., Pearson, O.H., Robbins, J., Poppell, H.F. \& WeST, C.D. (1953) L-Triiodothyronine versus $\mathrm{L}$-thyroxine. A comparison of their metabolic effect in human myxoedema. Amer. J. med. Sci. 226, 405.

SHARPEY-SCHAFER, E.P. (1955) Effects of Valsalva's manoeuvre on normal and failing circulation. Brit. med. $J$. $1,693$.

Society of Actuaries (1959) Build and Blood Pressure Study, Vol. 1. Chicago.

Soffer, L.J., IANnaccone, A., Wiener, R., Griboff, S.I. \& EISENBERG, J. (1954) Body fluids and electrolyte balance in myxoedema. Acta Endocr. (Kbh.), 17, 418.

SURVEYOR, I. (1967) The normal body composition as determined by combined radioactive isotope dilution and the changes in thyrotoxicosis, myxoedema and obesity; with special reference to the clinical value of determining the 1-hour exchangeable sodium. M.D. Thesis, University of Bristol, chapter 7.

Surveyor, I. \& Hughes, D. (1968) Discrepancies between whole-body potassium content and exchangeable potassium. J. Lab. clin. Med. 71, 464.

Veall, N. \& Vetter, H. (1958) Radioisotope Techniques in Clinical Research and Diagnosis. Butterworth, London.

VoGT, J.H. (1960) Impaired water excretion capacity in primary myxoedema improved by cortico-steroids, corticotrophin and thyroid substitution. Acta Endocr. (Kbh.), 35, 277.

Wiener, R., IAnnaccone, A., Eisenberg, J., Griboff, S.A., LUDWIG, A.W \& SOFFER, L.J. (1955) Influence of hormone therapy on body fluids, electrolyte balance and mucopolysaccharides in myxoedema. J. clin. Endocr. 15, 1131.

ZONDEK, H. (1944) The Diseases of the Endocrine Glands, 2nd edn, Chapter 12. Edward Arnold, London. 